\title{
Sosialisasi Etika Bermedia Sosial Untuk Menyikapi Berita Hoax Di SMA Muhamadiyah 4 Purbalingga
}

\author{
RETNO WALUYO ${ }^{1}$, NURIZZATUR ROHMAN MUQSITH ${ }^{2}$ \\ ${ }^{1,2}$ STMIK Amikom Purwokerto \\ Jln. Pol. Soemarto, Karangjambu, Purwanegara, Purwokerto \\ E-mail : waluyo@amikompurwokerto.ac.id
}

\begin{abstract}
Digital technology presents communication space and information media that are no longer limited by time and distance. Social media that allows anyone to argue. Hoax has become a hot topic in the mass media and social media lately because it is considered disturbing the public. The use of smartphones among high school / vocational students is inevitable and continues to increase, every time you can use a smartphone to open social media so that information can be easily accessed. Knowledge of students and teachers at Muhammadiyah 4 High School in Purbalingga related to the ethics of social media internet is still limited so it does not provide knowledge about the ethics of social media. Efforts to socialize social media ethics in order to fortify the 4 Purbalingga Muhamadiyah High School students from Hoak news circulating on the internet / social media and are expected to break the hoax news spread and also provide understanding so that students do not easily trust the news on social media. After the socialization of social media ethics was carried out to respond to hoax news, students knew the ethics of using social media to respond to the news hoax.
\end{abstract}

Keywords: Ethics, Social Media, Hoax

Teknologi digital menghadirkan ruang komunikasi dan media informasi yang tidak lagi terbatas oleh waktu dan jarak. Di media sosial kita bisa bebas berpendapat dan berekspresi, namun perlu ditegaskan bahwa kebebasan tersebut bukanlah kebebasan mutlak tanpa batas dan etika. Kementerian Komunikasi dan Informatika (Kemenkominfo) mengungkapkan pengguna internet di Indonesia tahun 2017 mencapai 143,26 juta jiwa atau setara dengan 54,68 persen dari total jumlah penduduk Indonesia. Jumlah tersebut menunjukan kenaikan sebesar 10,56 juta jiwa pada tahun 2016 (Kominfo, 2018).

Menurut data dari Webershandwick, perusahaan public relations dan pemberi layanan jasa komunikasi, untuk wilayah Indonesia ada sekitar 65 juta pengguna Facebook aktif. Sebanyak 33 juta pengguna aktif per harinya, 55 juta pengguna aktif yang memakai perangkat mobile dalam pengaksesannya perbulan dan di sekitar 28 juta pengguna aktif yang memakai perangkat mobile per harinya (Susanto, 2013).
Media sosial yang memungkinkan siapa saja untuk berpendapat, tanpa mengenal pangkat, ijazah, jabatan, kemudian menjadi sarana yang paling mudah untuk menggali informasi terkini (Nugroho, 2017).

Saat ini terjadi fenomena dimana media sosial digunakan untuk menyebarkan berita bogong atau hoax. sehingga beberapa kasus mengenai penyebaran berita hoax berurusan dengan aparat penegak hukum (Hadiyati, dkk, 2018).

Hoaxs menjadi perbincangan hangat di media massa maupun media sosial belakangan ini karena dianggap meresahkan publik dengan informasi yang tidak bisa dipastikan kebenarannya. Istilah Hoaxs, kabar bohong merupakan istilah dalam bahasa Inggris yang masuk sejak era industri, diperkirakan pertama kali muncul pada 1808. Asal kata "Hoaxs" diyakini ada sejak ratusan tahun sebelumnya, yakni "hocus" dari mantra "hocus pocus", frasa yang kerap disebut 
oleh pesulap, serupa "sim salabim" (Lynda, 2007).

Kabar bohong yang beredar di media sosial, menjadi besar ketika diambil oleh situs atau pelaku terkemuka yang memiliki banyak pengikut. Kecepatan dan sifat media sosial yang mudah untuk dibagikan, shareability berperan dalam penyebaran berita Hoax. Maraknya berita Hoax akan memberikan dampak negative bagi siapa saja. Kontennya biasanya berisi hal negative, yang bersifat hasut dan fitnah. Hoax akan menyasar emosi masyarakat, dan menimbulkan opini negative sehingga terjadi disintergratif bangsa.

Jenis-jenis Informasi Hoax (rahadi, 2017):

1. Fake news: Berita bohong: Berita yang berusaha menggantikan berita yang asli. Berita ini bertujuan untuk memalsukan atau memasukkan ketidakbenaran dalam suatu berita. Penulis berita bohong biasanya menambahkan hal-hal yang tidak benar dan teori persengkokolan, makin aneh, makin baik. Berita bohong bukanlah komentar humor terhadap suatu berita.

2. Clickbait: Tautan jebakan: Tautan yang diletakkan secara stategis di dalam suatu situs dengan tujuan untuk menarik orang masuk ke situs lainnya. Konten di dalam tautan ini sesuai fakta namun judulnya dibuat berlebihan atau dipasang gambar yang menarik untuk memancing pembaca.

3. Confirmation bias : Bias konfirmasi : Kecenderungan untuk menginterpretasikan kejadian yang baru terjadi sebaik bukti dari kepercayaan yang sudah ada.

4. Misinformation: Informasi yang salah atau tidak akurat, terutama yang ditujukan untuk menipu.

5. Satire: Sebuah tulisan yang menggunakan humor, ironi, hal yang dibesar-besarkan untuk mengkomentari kejadian yang sedang hangat. Berita satir dapat dijumpai di pertunjukan televisi
6. Post-truth:

Pasca-kebenaran: Kejadian di mana emosi lebih berperan daripada fakta untuk membentuk opini publik.

Penggunaan

smartphone dikalangan pelajar SMA/SMK sudah tidak dapat terhindarkan lagi dan terus meningkat, setiap waktu dapat menggunakan smartphone untuk membuka media sosial sehingga mendapatkan informasi dengan mudah, informasi yang berkembang dimedia sosial tidak semuanya benar, ada informasi yang Hoaxs dengan sengaja disebarkan untuk kepentingan tertentu. kondisi ini memerlukan sebuah tindakan untuk mewujudkan internet sehat dan aman di kalangan remaja. Dengan kegiatan sosialiasi diharapkan para peserta dapat mengetahui etika menggunakan media sosial.

Pengetahuan siswa maupun Guru di SMA Muhamadiyah 4 Purbalingga terkait etika bermedia sosial internet masih terbatas sehingga tidak memberikan pengetahuan mengenai etika bermedia sosial, dengan adanya Program Pengabdian kepada Masyarakat dalam bidang Teknologi Informasi dan Ilmu Komputer ini dapat menjadi salah satu upaya untuk mensosialisasikan etika bermedia sosial agar bisa membentengi Siswa-siswi SMA Muhamadiyah 4 Purbalingga dari berita Hoak yang beredar di internet/media sosial dan diharapkan dapat memutus berita hoax tersebar dan juga memberikan pemahaman agar para siswa tidak mudah percaya dengan berita yang ada di media sosial.

\section{METODE}

Metode yang digunakan adalah dengan cara pendekatan kepada masyarakat meliputi monologis dan dialogis. Monologis yaitu presentasi penyampaian materi dan dialogis berupa wawancara atau tanya jawab dengan peserta sosialisasi guna mengetahui tingkat pemahaman berkaitan etika bermedia sosial. 


\section{HASIL}

$\begin{array}{lr}\text { Kegiatan Pengabdian } & \text { Kepada } \\ \text { Masyarakat dilaksanakan di SMA }\end{array}$ Muhamadiyah 4 Purbalingga. Pengabdian ini sebagai bentuk tanggung jawab kami sebagai dosen melaksanakan kegiatan Tri Dharma Perguruan tinggi. Dalam pelaksanaan pengabdian ini kami melibatkan mahasiswa dengan tujuan untuk melatih mahasiswa terlibat dalam kegiatan di masyarakat. Judul kegiatan ini adalah "Sosialisasi Etika Bermedia Sosial Untuk Menyikapi Berita Hoax Di Sma Muhamadiyah 4 Purbalingga". Berdasarkan uraian di atas dapat digambarkan skema permasalahan, potensi, pemecahan masalah, dan target luaran kegiatan pengabdian tahun 2018 sebagai berikut :

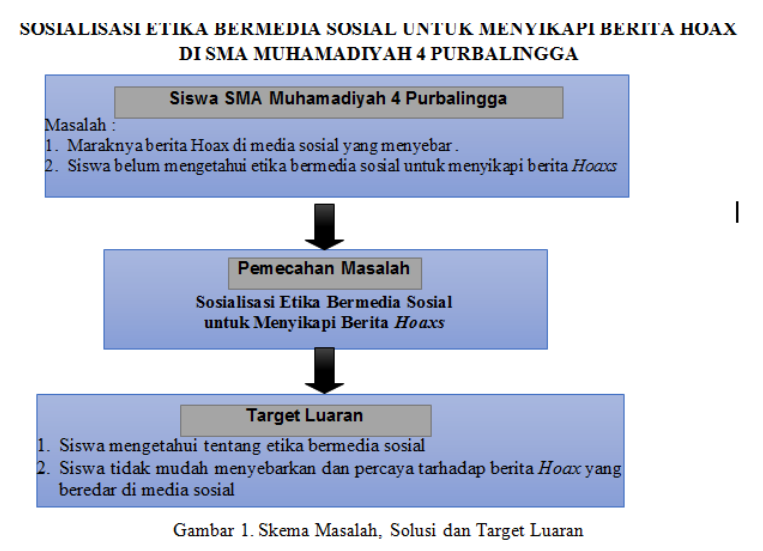

\section{PEMBAHASAN}

Kegiatan

pengabdian kepada masyarakat yang kami laksanakan di SMA Muhamadiyah 4 Purbalingga selama 1 hari pada tanggal 10 Agustus 2018, berikut rincian kegiatan yang kami laksanakan:

Pada tanggal 10 Agustus 2018 pelaksanaan dimulai, Tim dari STMIK Amikom Purwokerto mendatangi mitra pada pukul

\begin{tabular}{|l|l|l|}
\hline No & Waktu & Kegiatan \\
\hline 1 & $08.00-$ & Penyampaian Materi Etika \\
& 11.30 & Bermedia Sosial \\
\hline 2 & $11.30-$ & Ishoma \\
& 13.00 & \\
\hline 3 & $13.00-$ & Tanya Jawab \\
& 14.00 & \\
\hline
\end{tabular}

07.00 untuk melakukan koordinasi sebelum pelaksanaan dimulai. Sampai di tempat mitra kami menemui kepala SMA Muhamadiyah 4
Purbalingga untuk meminta ijin akan dilaksanakan kegiatan Sosialisasi. Kepala sekolah menyambut dengan baik kegiatan yang akan dilaksanakan beliau berharap kegiatan yang kami laksanakan dapat menambah pengetahuan siswa dan berharap untuk selanjutnya dapat dilakukan kembali dengan tema yang berbeda. Pada Pukul 07.30 Tim dari STMIK Amikom Purwokerto bersama Guru BK menuju ke Ruang kelas yang ada di SMA Muhamadiyah 4 Purbalingga sebagai tempat pelaksanaan sosialisasi. Acara dimulai dengan sambutan dari mitra yang diwakili oleh Guru BK. Dalam sambutannya beliau menyampaikan agar peserta mengikuti serta memperhatikan dengan baik selama kegiatan dilaksanakan. Harapan dari beliau agar kegiatan seperti ini dapat rutin dilaksanakan di SMA Muhamadiyah 4 Purbalingga untuk menambah wawasan siswa. Pada pukul 08.00 WIB kami mulai melakukan kegiatan utama yaitu memberi materi etika bermedia sosial untuk menyikapi berita hoax. Pada pukul 11.30 WIB kegiatan diberhentikan sementara untuk kegiatan istirahat, sholat dan makan. Pada pukul 13.00 WIB kegiatan kembali dimulai dengan melakukan sesi tanya jawab dengan siswa sampai jam 14.00 WIB. Kemudian dilanjutkan dengan penutupan acara oleh guru BK. Adapun Pelaksanaan Kegiatan Pengabdian Masyarakat di SMA Muhamadiyah 4 Purbalingga kami jadwalkan sebagai berikut:

Pelaksanaan kegiatan pengabdian berlangsung pada :

Hari / Tanggal : Jum'at / 10 Agustus 2018

Pukul : $08.00-14.00$ WIB

Tempat : SMA Muhamadiyah 4 Purbalingga

Peserta : 31 Peserta

Kegiatan berupa sosialisasi etika bermedia sosial dengan penjelasan sebagai berikut:

Tabel 1. Jadwal Kegiatan Pengabdian Kepada Masyarakat

Berdasarkan hasil wawancara dan pengamatan langsung selama kegiatan berlangsung siswa memahami etika 
menggunakan media sosial. Sehingga siswa tidak mudah untuk menyebarkan dan mempercayai berita Hoax yang beredar di media sosial.

Berdasarkan hasil pelaksanaan kegiatan yang telah dilakukan, dapat ditarik beberapa simpulan bahwa Kegiatan pengabdian masyarakat dengan judul "Sosialisasi Etika Bermedia Sosial Untuk Menyikapi Berita Hoax Di SMA Muhamadiyah 4 Purbalingga " berjalan dengan baik. Siswa mengetahui etika menggunakan media sosial untuk menyikapi berita Hoax.

Sebagai generasi muda diharapkan lebih bijak menggunakan media sosial untuk menghindari berita hoax. Dampak positif dan negatif sosial media di atas tidak akan terjadi apabila remaja itu pandai memanfaatkan sosial media tersebut dengan baik dan benar.

Hal ini sejalan dengan pendapat Hadiyati, (2018) bahwa perlu adanya upaya nyata bagi pelajar untuk mengetahui cara menilai berita hoax yang benar, sehingga tidak terjebak dalam kesesatan informasi. Kemudian juga disampaikan. Juga disampaikan oleh Fatkhurahman, F. (2018) bahwa mengenai berita hoax bagi siswa, selain sebagai fenomena kebohongan juga menjadi sebuah gambaran kegagalan berpikir yang benar.

\section{SIMPULAN}

Berdasarkan uraian di atas, dapat diketahui bahwa Pengetahuan siswa maupun Guru di SMA Muhamadiyah 4 Purbalingga terkait etika bermedia sosial internet masih terbatas sehingga tidak memberikan pengetahuan mengenai etika bermedia sosial. Upaya untuk mensosialisasikan etika bermedia sosial agar bisa membentengi Siswa-siswi SMA Muhamadiyah 4 Purbalingga dari berita Hoak yang beredar di internet/media sosial dan diharapkan dapat memutus berita hoax tersebar dan juga memberikan pemahaman agar para siswa tidak mudah percaya dengan berita yang ada di media sosial. Setelah dilaksanakan kegiatan Sosialisasi Etika Bermedia Sosial Untuk Menyikapi Berita Hoax Siswa mengetahui etika menggunakan media sosial untuk menyikapi berita Hoax.

\section{DAFTAR RUJUKAN}

Antaranews.com.http://www.antaranews.co $\mathrm{m} /$ berita/605171/apa-itu-hoax.

Ayobandung.com.http://ayobandung.com/re $\mathrm{ad} / 20161124 / 63 / 13318 /$ kemenkom info-media-sosial-berpotensi-picukonflik.

Cnnindonesia.com.https://www.cnnindones ia.com/teknologi/20161024161722 -185-167570/pengguna-internet-diindonesia-didominasi-anak-muda/.

Fatkhurahman, F. (2018). Kemampuan Mahasiswa Tempatan Menilai Berita Palsu Atau "Hoax" Dalam Media Sosial Dalam Upaya Pengembangan Jiwa Kewirausahaan. Jurnal Benefita: Ekonomi Pembangunan, Manajemen Bisnis Dan Akuntansi, 3(3), 417-426.

Hadiyati, H., Fatkhurahman, F., \& Suroto, B. (2018). Evaluasi Pelatihan Menilai Berita Palsu atau "Hoax" Pada Kelompok Arisan Dosen Perempuan. Jurnal Diklat Review, 2(2), 106-112.

Lynda Walsh. (2007), Sins Against Science: The Scientific Media Hoaxes of Poe, Twain, and Others, State University of New York Press.

Merdeka.com,2013,https://www.merdeka.c om/teknologi/data-terkinipengguna-facebook-diindonesia.html.

Nugroho, S. E. (2017). Upaya masyarakat anti fitnah indonesia mengembalikan jatidiri bangsa dengan gerakan anti hoax. 
250 Sosialisasi Etika Bermedia Sosial Untuk Menyikapi Berita Hoax Di SMA Muhamadiyah 4 Purbalingga

Prosiding konferensi nasional peneliti muda psikologi indonesia, 2(1), 1-4.

Rahadi, Dedi Rianto. (2017). Perilaku Pengguna Dan Informasi Hoax Di Media Sosial. Jurnal manajemen . vol .5. No. 1.

Siaran Pers NO. 53/HM/KOMINFO/02/2018 Tentang Jumlah Pengguna Internet 2017 Meningkat, Kominfo akan Terus Lakukan Percepatan Pembangunan Broadband. 